\title{
Software Solution of Web Questionnaires for the Analysis of the Economy in Relation to the Competence of Students
}

\author{
Vlado Simeunović \\ Sanja Milic ${ }^{2}$ \\ 1,2Faculty of Education Bijeljina, University of East Sarajevo, Bosnia and Herzegovina \\ E-mailivlado.simeunovic@pfbules.rs.ba Tel: +38765926909 \\ 'E-mailivilado.simeunovic@pfb.ues.rs.ba Tel: +38765926
}

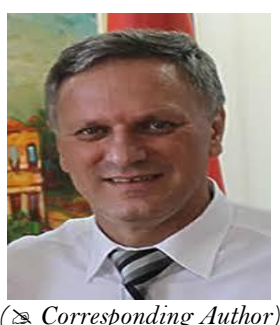

\begin{abstract}
The basic idea of the research was to take advantage of IT and establish a direct contact between businesses (employers) and universities in order to exchange relevant data on the knowledge, skills and competencies of students who got their first job in the economy. We used the best practices from previous papers that dealt with designing web questionnaires to more or less similar theme. We created the instruments for data collection which represent the essence of the research, conducted the survey, and programmed the software. The questionnaire is based on Likert-type questions. The programming is done in familiar web technologies. Relying on existing theoretical knowledge we modeled the research, and we are in the first part we constructed an instrument (a questionnaire with 44 questions of Likert type), performed necessary determining of its metric values, and then created a web application for its easy use. As a result of the specific method of programming and designing of pages, we got a functional software that presents web questionnaire which employers can access and evaluate newly hired students.
\end{abstract}

Keywords: Web questionnaire, Economy, Students, Software, Faculty, Employers.

Citation | Vlado Simeunović; Sanja Milic (2018). Software Solution of Web Questionnaires for the Analysis of the Economy in Relation to the Competence of Students. Asian Journal of Education and Training, 4(1): 1-8.

History:

Received: 12 December 2017

Revised: 28 December 2017

Accepted: 4 January 2018

Published: 10 January 2018

Licensed: This work is licensed under a Creative Commons Attribution 3.0 License $(\mathrm{cc}) \mathbf{E}$

Publisher:Asian Online Journal Publishing Group
Contribution/Acknowledgement: Both authors contributed to the conception and design of the study.

Funding: This study received no specific financial support

Competing Interests: The authors declare that they have no conflict of interests.

Transparency: The authors confirm that the manuscript is an honest, accurate, and transparent account of the study was reported; that no vital features of the study have been omitted; and that any discrepancies from the features of the study have been omitte
study as planned have been explained.

Ethical: This study follows all ethical practices during writing

\section{Contents}

1. Introduction

2. Review of Literature

3. Metodology ...

4. Results.

5. Conclusion

References... 


\section{Introduction}

Given that knowledge is one of the most important resources of development of any society, many countries in the world, as well as the Republic of Srpska (BiH), through the reform of higher education are constantly trying to contribute to the development of the national economies (Vlada Republike Srpske, 2015). The European Commission has a vision that 'the contribution of higher education to economic growth and employment can be increased only in the continuing integration of education, research and innovation - the three sides of the 'knowledge triangle'. In the same report, which includes all EU countries, twelve countries said the problem needs continuous monitoring of newly achieved competence of students in order to raise the efficiency of higher education (Ministarstvo Civilnih Poslova BiH, 2011). Some of these countries in the reports cited negative interrelationship between these two important segments of social development.

The above views were expressed fifty years ago in the work of American economist Theodore (1961) which proves that the skills and knowledge are forms of capital. Success can be achieved only by producing high quality goods and services that cannot be achieved anywhere else. In order to be positioned in the global market, companies must provide competitive and high quality offer. Such competitiveness can only be achieved with the help of the workforce that has received the best possible education and training and which is to be improved for the entire service life.

The focus is placed on the obligation of universities to monitor changes in both social and technological development in order to meet the educational needs of the changeable business environment. Although we can not expect to solve all the problems of society through activities in higher education, it is desirable to determine the attitude of employers towards the key competencies that students acquire at higher education institutions. Employers are mainly interested in which generic skills and knowledge students acquire during their education, whether it is the skills that are immediately applicable in practice or academic knowledge of high level with high indicators of generality that abound in knowledge of the basic concepts and principles with a slim chance that without additional training turn to the work ability. Certificates that students receive are mainly of the same (template) method, and competencies that are attributed to a student are generally not consistent with real knowledge. In practice, the range is from a minimum of knowledge to that that enables a successful independent practice.

There is concern that the current curricula do not allow students to acquire the knowledge, skills and habits they need to be successful in their professions. One of the main problems is related to the capacity for lifelong learning, which includes, besides knowledge, acquired working habits, intellectual skills and the necessary level of motivation.

This paper is based on the above facts. The focus was on solving the problems that are reflected in the empty space that exists in communication between companies and universities when it comes to profiling of professionals. The idea is that there is an online questionnaire available in all schools, through which the company would be able to fully evaluate newly hires students. This would eventually improve the understanding of the demands made by the company in the recruitment of new staff.

The rest of the paper is organized as follows. The following section provides an overview of some of the most important studies that have been conducted on this topic. Detailed description of the methodology and models is available in the section 3. The section 4 describes the final product, i.e. software, and the results that were obtained. Chapter 5 provides conclusions and messages to improve the software.

\section{Review of Literature}

In the paper "Conducting Research on the Internet: Online Survey Design, Development and Implementation Guidelines" (Andrews et al., 2003)they state functionalities that electronic questionnaire should possess, including: (1) support multiple platforms and browsers, (2) prevent multiple responses from the same user, (3) to be designed as to represent the questions in a logical and natural manner, (4) provide the option to save the operation if it is a long questionnaire (more than 50 questions), (5) collect answers to closed and open questions, (6) provide feedback part for the intended user.

They also mention some of the benefits offered by online questionnaires compared to conventional ones. These advantages are reflected in the low cost and fast distribution to a large number of respondents, followed by the ability that responses are automatically recorded in the database, eliminating errors in transcription/interpretation of the answers, as well as preventing any modification of the questionnaire by the user.

These advantages are confirmed by Schleyer and Forrest (2000) in the paper "Methods for the Design and Administration of Web-based Surveys" and add that it is very important that the application is thoroughly tested before launch in order to eliminate software defects or certain incompatibilities. Some of the variables which allow the software to be tested are different operating systems, browsers, types of Internet connection, etc. As they say, a systematic approach to identifying these and other variables and their testing significantly reduces the chance of failure when the software is delivered to users.

Schleyer and Forrest (2000) once again emphasize the process of pilot testing, and they claim that it is very important that the sample on which it is to be carried out must be big enough. Careful analysis of the first results may indicate errors which have been observed prior to a user interaction with the software - from technical to semantic errors. Small errors that can reduce the validity of the data are more likely to happen in online questionnaires than in conventional surveys, because every user has different experiences of questionnaire based on the size of the screen from which you read, platforms, browsers, Internet connection, etc. These, they say, are the real phenomena that must be taken into account, and many who develop online questionnaires ignore them. On the other hand, regarding the topic of this paper, numerous studies have been conducted to determine what competencies employers recognize in new recruits and those which they lack, namely those which are necessary for functioning in the business world. Accordingly, the Association of Graduate Recruiters - AGR (1995) with the theme of Skills for Graduates in the 21 st Century, Vescio (2005) Australian Association of Australian Association of Graduate Employers - AAGE. (1993);Andrews and Higson (2008);Simeunović (2009) show that employers successfully recognize skills, positive attitude, motivation, but also often emphasize the lack of communicative 
competence, insufficient capacity for teamwork, initiative, dedication, perseverance and similar skills that employers require from employers.

In support of the Bologna process there is in place a program of harmonization of educational structures and competences in Europe (Gobbi, 2005). Tuning project focuses on two different sets of competences - generic competences and a branch-specific competencies. Generic (General) competences are a set of knowledge, skills and values that are widely used in various fields of activity and allow flexible adaptation to a variety of highly skilled jobs. These qualities and skills are common to all study levels and certain social groups consider them important. According to Tuning, the competences are: instrumental competence (cognitive abilities, methodological abilities, technical skills and linguistic skills), interpersonal competence (individual abilities like social skills), systemic competencies (abilities and skills relevant to the systemic approach (combination of understanding, sensibility and knowledge). Regional-specific competencies are the backbone of every level of the study program and are associated with appropriate expertise in certain fields of study. They are also called academic competence, because they characterize and determine the study program and give it consistency.

European economies rely on producing and applying knowledge (2015). Strong links between business and higher education are essential. Businesses are increasingly involved in European education and training programs (2008), with positive results for both sides, leading to long-term partnerships.

As an example of this attitude are elements of the Erasmus programs (2015), which are offered to business and education sectors in the European area of education:

- Practice for students: students gain work experience in a company abroad for up to one year;

- "The mobility of staff" for learning: company staff acquires skills at higher education institutions;

- $\quad$ "Staff mobility" for training: teaching and other staff can gain experience and explore in foreign companies;

- Cooperation: representatives of the business sector or representative associations may participate in projects through strategic partnerships, capacity-building projects and the creation of 'knowledge alliances'.

Thus, the essential aim of this project is to raise awareness in our business and academic community on the need for joint action in the way of a developed society based on knowledge, skills and innovation.

\section{Metodology}

The main objective of the research is focused on software development that will serve to collect information from employers about their vision of competences of graduates who are employed in certain enterprises. The plan is that the software be installed in all schools so that any employer can assess the student who is employed with the employer after leaving from a specific college. The ultimate goal and basic purpose of the program is to enable employers to indicate to managers at the University the strongest and weakest sides of applied curricula, in order to modify these programs to labor market needs.

We assumed that this research will create the elements for a successful programming software for data collection from employers about the competence of graduate students.

Based on the research results to program and create software for data collection from employers about the competence of students who graduated.

\subsection{Methodological Preparation of the Instrument for Information Gathering}

Methodological preparation of the instrument for examining the attitudes of employers about the competences of graduates included the development and validation of the instrument applied to the sub-sample in the preliminary research stage.The population of the research consisted of 553 trainees employed in the 'Project for hiring apprentices'.

The study sample consisted of 102 trainees who were employed in the territory of the Branch Employment in Bijeljina.

For the study we constructed a questionnaire of 46 questions of Likert type where employers are able on a scale of 1-5 from their perspective to indicate whether graduates possess characteristics, abilities, skills and knowledge to perform the job effectively. Questions have been constructed so that in the latent way features (competences) may be recognized as the key ones, as follows:

1. Creativity and Innovation (because it will allow employers greater success and competitiveness of companies in the market);

2. The ability of critical and analytical thinking, logical reasoning and decision-making;

3. Social and interpersonal skills (communication, teamwork, responsibility);

4. The ability of clear expression (both verbal and written);

5. Ability to apply knowledge in real life;

6. Ability of solving complex problems (identification and analysis of the problem, the formulation of test solutions and their testing);

7. Ability for lifelong training (Economic and technological development, especially the development of information technology have changed the traditional ways of working, requiring new and different abilities and skills, not only professionally, but also in the ability of production, analysis and transformation of information and effective interaction and cooperation with others . Learning becomes a lifelong activity.)

8. Multiple technical skills and knowledge (Employees are now faced with increasing and varied challenges. A large number of employers consider it very important owning a wide range of skills and knowledge in addition to the basic one that is required for a particular job to be filled in).

For all the evaluation scales an explanatory factor analysis was performed (component analysis with varimax rotation) for determining the dimension of the latent instruments. Criteria for the extraction of factors, with the Guttman-Kaiser criterion was their interpretability. We then calculated the coefficient of reliability (Cronbach a) for all four scales of assessment, as well as for the entire instrument.

With factoral analysis we have selected four factors, which we defined as personal qualities, communication skills and understanding of human relationships, intellectual abilities and generic and specific skills and knowledge. 
Substantially the instrument measures four constructs covering $81 \%$ of the total variance, which proves the validity of the instrument. To compute the internal consistency (Cronbach a) for the scale of personal characteristics it is 0.79 ; the intellectual abilities 0.76 ; the ability to communicate and understand interpersonal relationships 0.82 for generic and specific skills and knowledge 0.80 . All coefficients are significant, but the overall reliability of the instrument is 0.84 .

Initial research has given us the basis to approach the development of web questionnaire with which we can relatively easily over a longer period of time collect relevant data on the needs of the economy and in the context of key competencies that are acquired at the university.

\subsection{Software Development}

For the purpose of this study we developed a special software appropriate to the circumstances of functioning in our environment. Existing tools LimeSurvey or SurveyMonkey could not be used for this work but we had to develop a specific solution. Advantage of having our own solution is the possibility of integration with the information system of student services and other information resources at the university where it is possible to reach precise conclusions regarding the competence of graduates.

For programming software we used web technologies as follows: PHP, HTML5, CSS (for web site design), Javascript for functionality, i.e. specifically to check the entered data. We used MySQL database.

When checking the code we checked line by line. In the initial phase of testing we gave the answer to every question, and the corresponding entry is checked in the database. The questionnaire is programmed to validate each page, i.e. to determine whether an answer was given to every question, that personal data are entered correctly (year, evaluation...).

Testing was conducted on several browsers. The program showed no error in testing. The principle of "sequential screens" was used that enabled a complete view of issues with a particular party, and thus prevented the need for a user to scroll excessively and potentially "get lost" in the questions.

Index page (index.html) was designed that contains all the elements of the user login and data entry for survey. It is also used to administer users when opening the administrative part of the site. It uses the following technologies: HTML and CSS to design web pages.

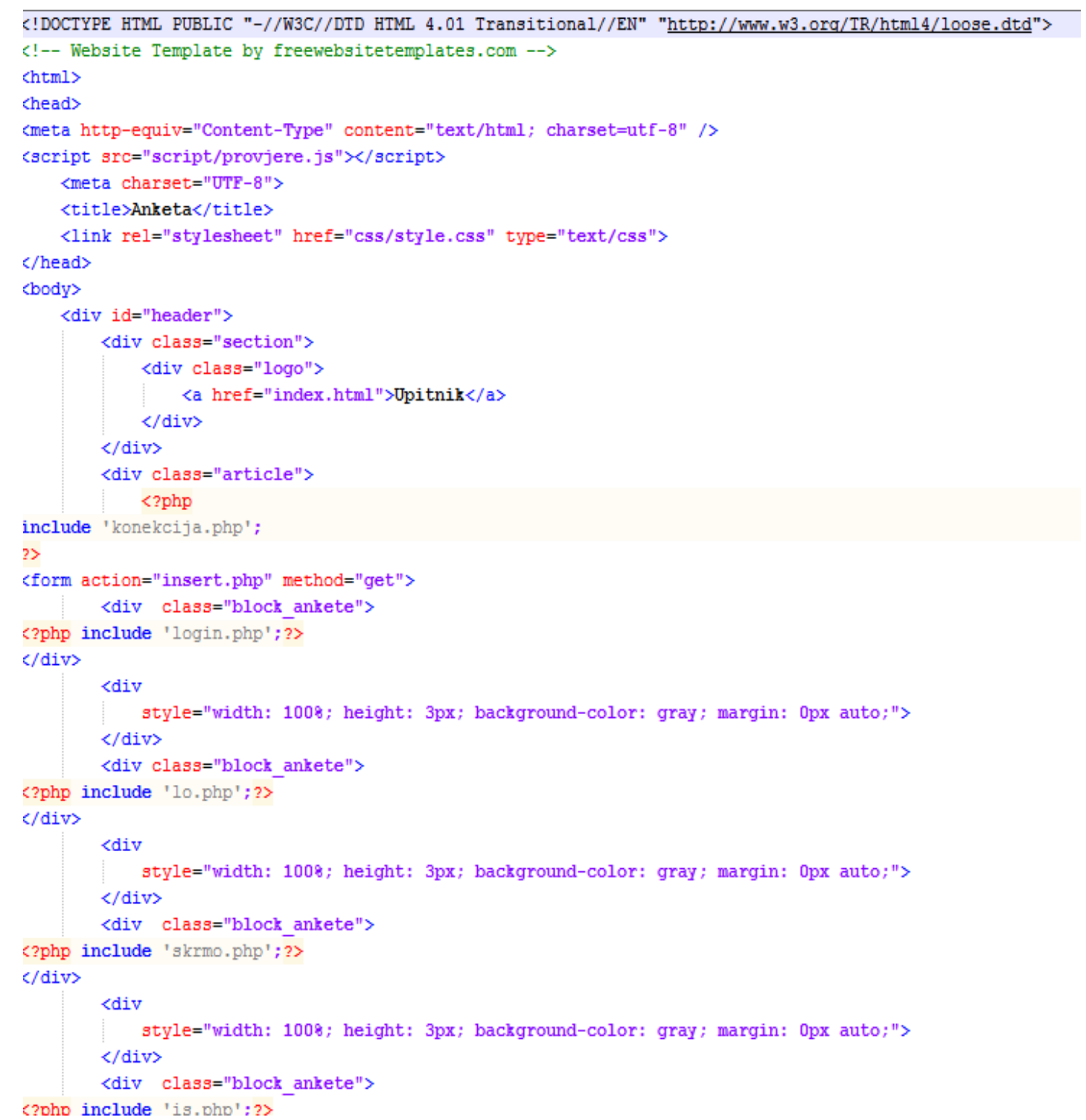

Source: From data collected

Fig-1. Index html

At the beginning the initializing of the variables that the application will use is done. The variable that indicates the position is defined which shows the current user is by using a multidimensional array: varpos $=0$, test, test_status, question, choice, choices, choiceA, choiceB, choiceC, choiceD, choiceE. Then one more multidimensional array containing all the questions is created. Through the property innerHTML we defined the type of response, in this case the checkbox so that when the user selects an answer to the question, Javascript will 
be able to return the value for the question to be answered.

Since the questionnaire contains a large number of question, the list of all the questions is in the file listofQuestions.js which we included in the file where we define the structure of questons. $<$ script src $=$ "listofQuestions.js">

All the user's responses are stored in the database.

A special page has been created for the user login - enter your login institutions, headquarters, activities, years of employment, degrees, titles, ratings. These data are forwarded from insert.php method on a page that is exclusively used for entry into the database.

Page for entering data for the survey - is defined in the same way as the page to enter personal data, except that on this page are entered data such as communication skills and understanding of human relations, intellectual abilities, generic and specific skills and knowledge. As stated in transition to the login user, this information is also forwarded from insert.php method on a page that is exclusively used for entry into a database, provided that previously is executed a check of data such as whether the user has entered all the necessary information.

The method of checking the entered data is written in JavaScript i.e. executed on the user page so that the data is not sent first to the server to check, but this is done directly by the user, and then he is informed of the faults of entered data or lack of data at the input of the survey. The advantage of this system is that it reduces the consumption of network resources and servers for data verification. This leads to a higher speed of operation of the website. Data validation is implemented using the Parsley validation framework.

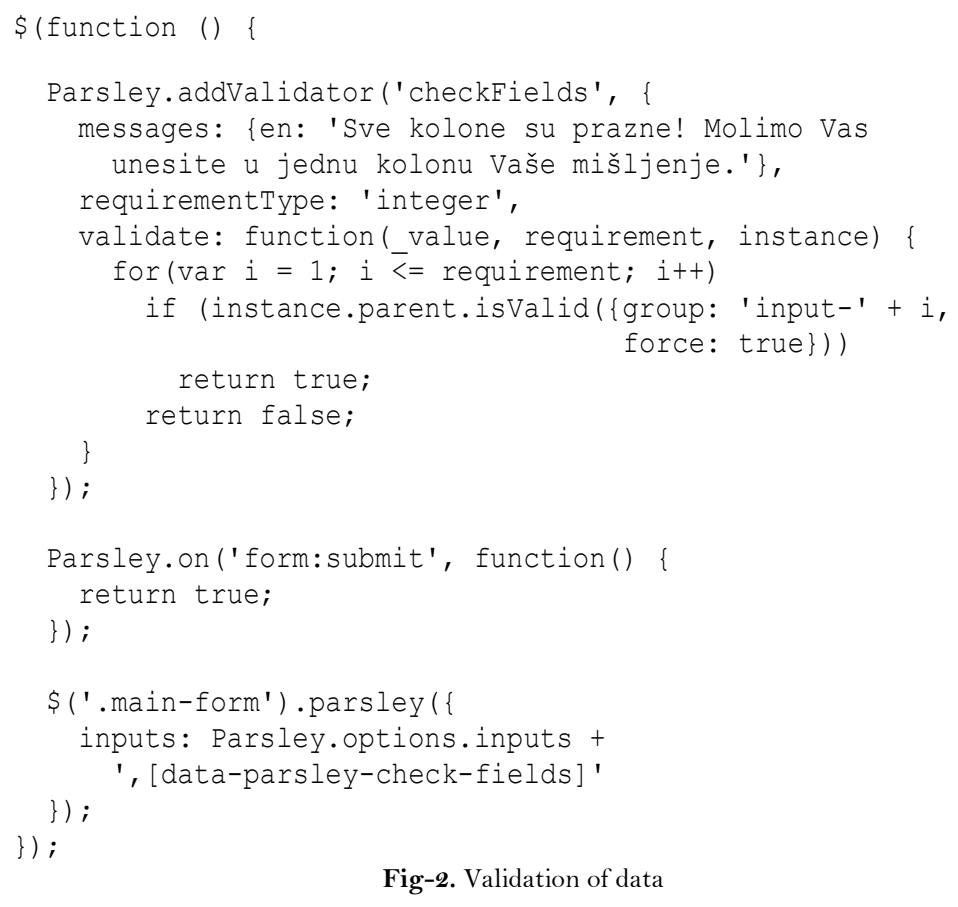

Fig-2. Validation of data

Source: From data collected

The methods for entering the data entered by the user - the code is executed after a successful data validation by the Javascript method, and only after that it is possible to enter valid data in the database. The data entry is based on the following methods in PHP: mysql_query, mysql_fetch_array, mysql_free_result, mysql_close and header.

1. mysql_query - This PHP method is used for various need during entering data, such as: SELECT, INSERT, UPDATE, DELETE, i.e. during exerting, inserting, updating or deleting the data from the database;

2. mysql_fetch_array - it is used mainly when from the previous question (select) we pull out the syllables of data from the question itself;

3. mysql_free_result - releasing the values from the question for cleaning the objects from the server after the entered data and into the database;

4. mysql_close - method used for closing the connection with mysql service;

5. header - PHP function that is used for forwarding into the next page as, for example, going back to the index page after entering data.

Administration of data - In this segment we can see all the information entered by the survey. In this part we used methods and the JavaScript functions to print values in the fields on the screen, mysql to read data that is forwarded from the base of the user's needs and HTML and CSS to display the view and web site design. 


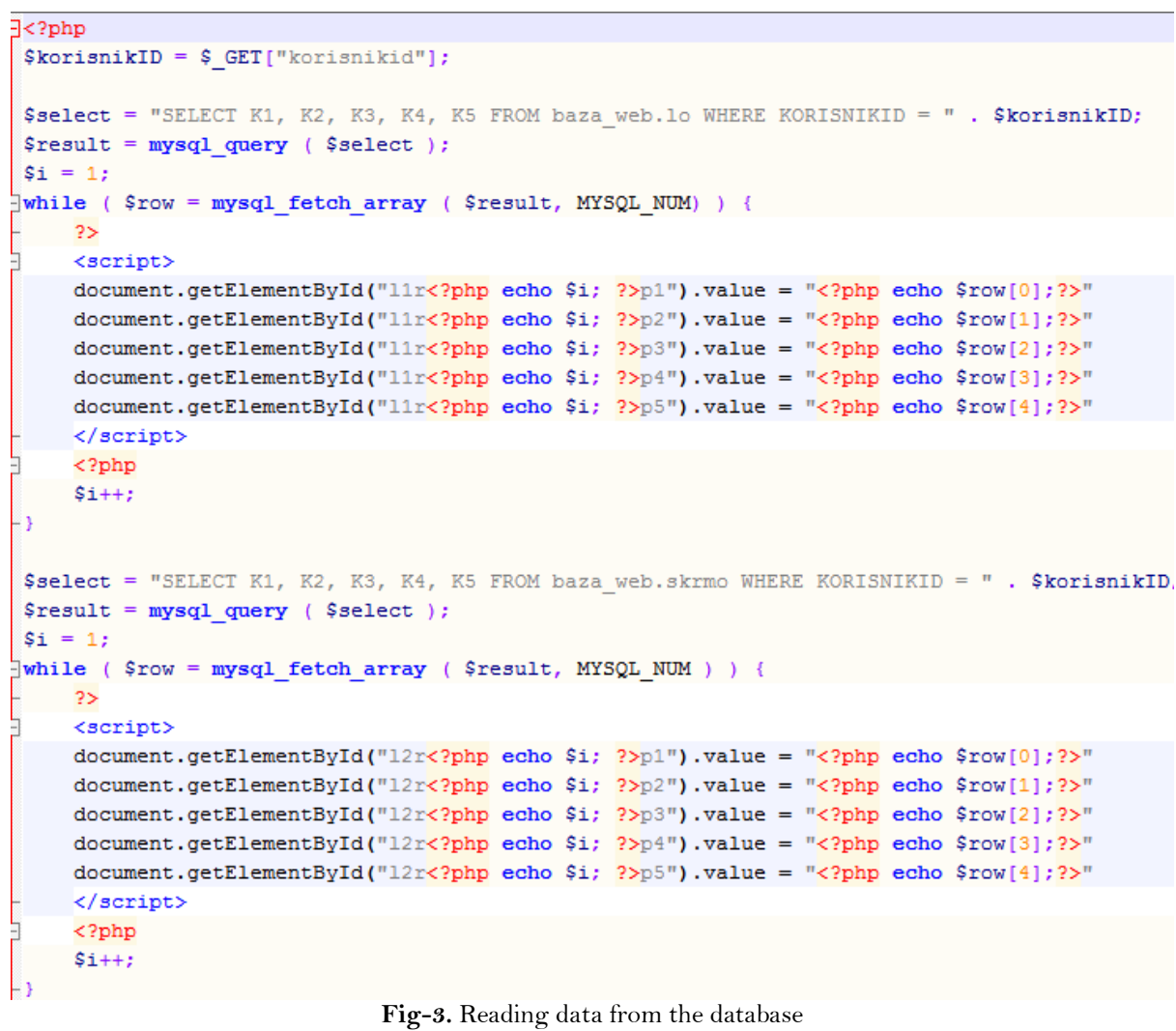

Fig-3. Reading data from the database

Source: From data collected

\section{Results}

As a result of the specific method of programming and designing of pages, we got a functional software that presents web questionnaire which employers can access and evaluate newly hired students.

We present also the UML Use Case dijagram:

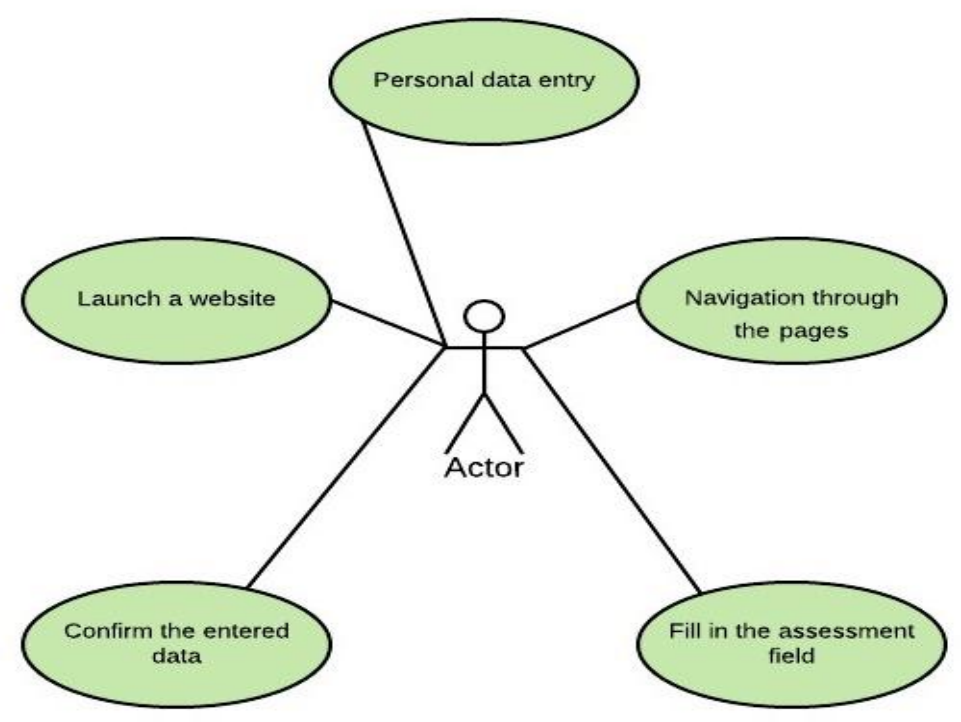

Fig-4. Use case diagram

For the purpose of understanding the simplest use of the website, we herewith describe a specific case, through the steps.

1. The user runs the site and as a view gets a home page with a form for data entry: 


\section{QUESTIONNAIRE}

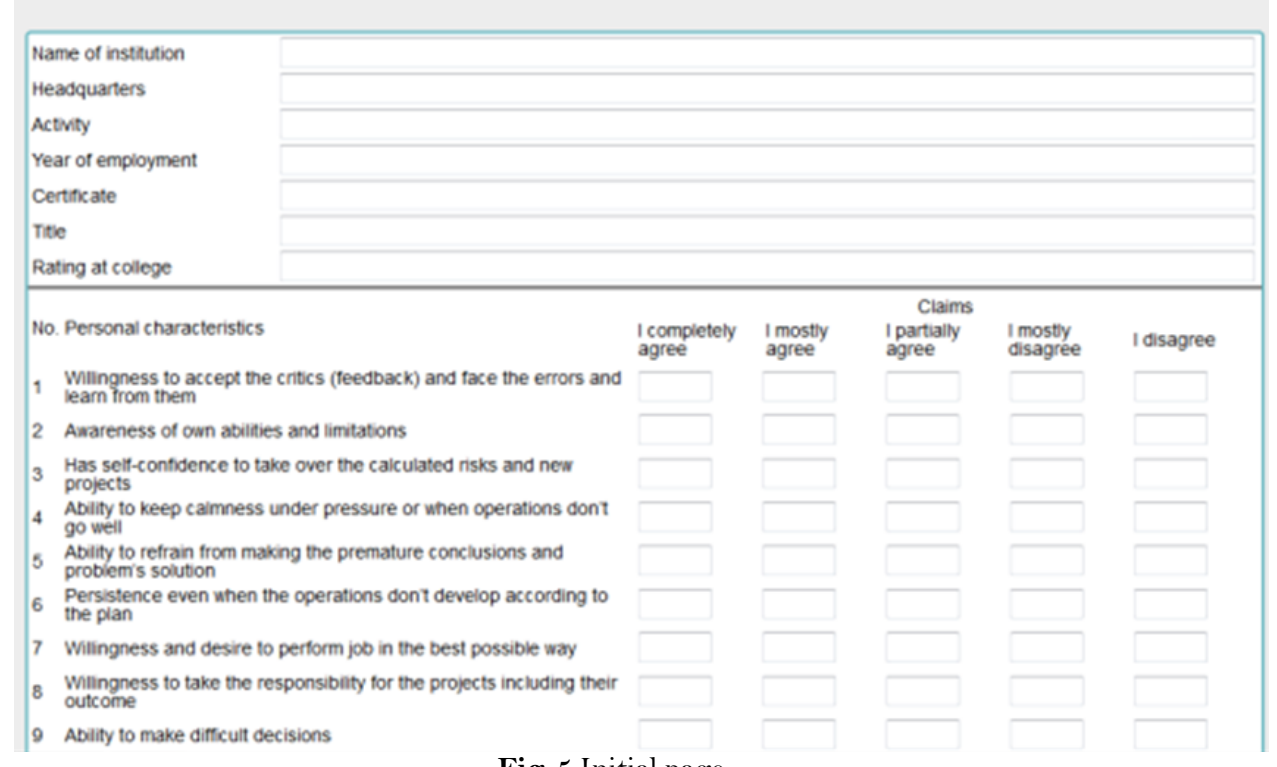

Fig-5.Initial page

2. He fills in personal data (Figure 5);

3. The first part of the evaluation of the employee which user is filling refers to the personal attributes of the employee (Figure 6);

4. The second part relates to the evaluation of the ability to communicate and understand interpesonal relationships (Figure 6);

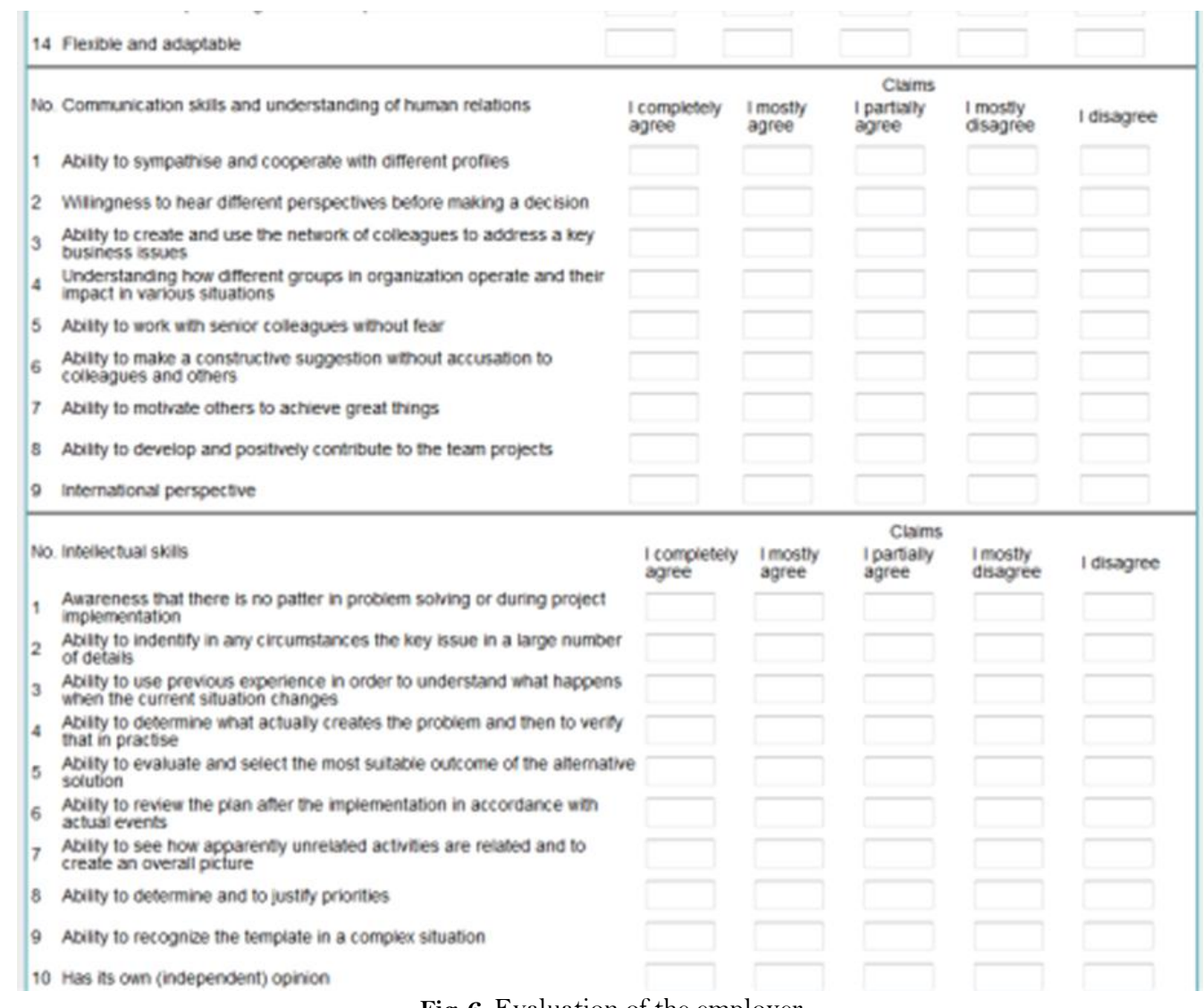

Fig-6. Evaluation of the employer

5. The third part comprises the intellectual capabilities of the employed (Figure 6);

6. In the fourth part generic and specific skills and knowledge are evaluated (Figure 7). 


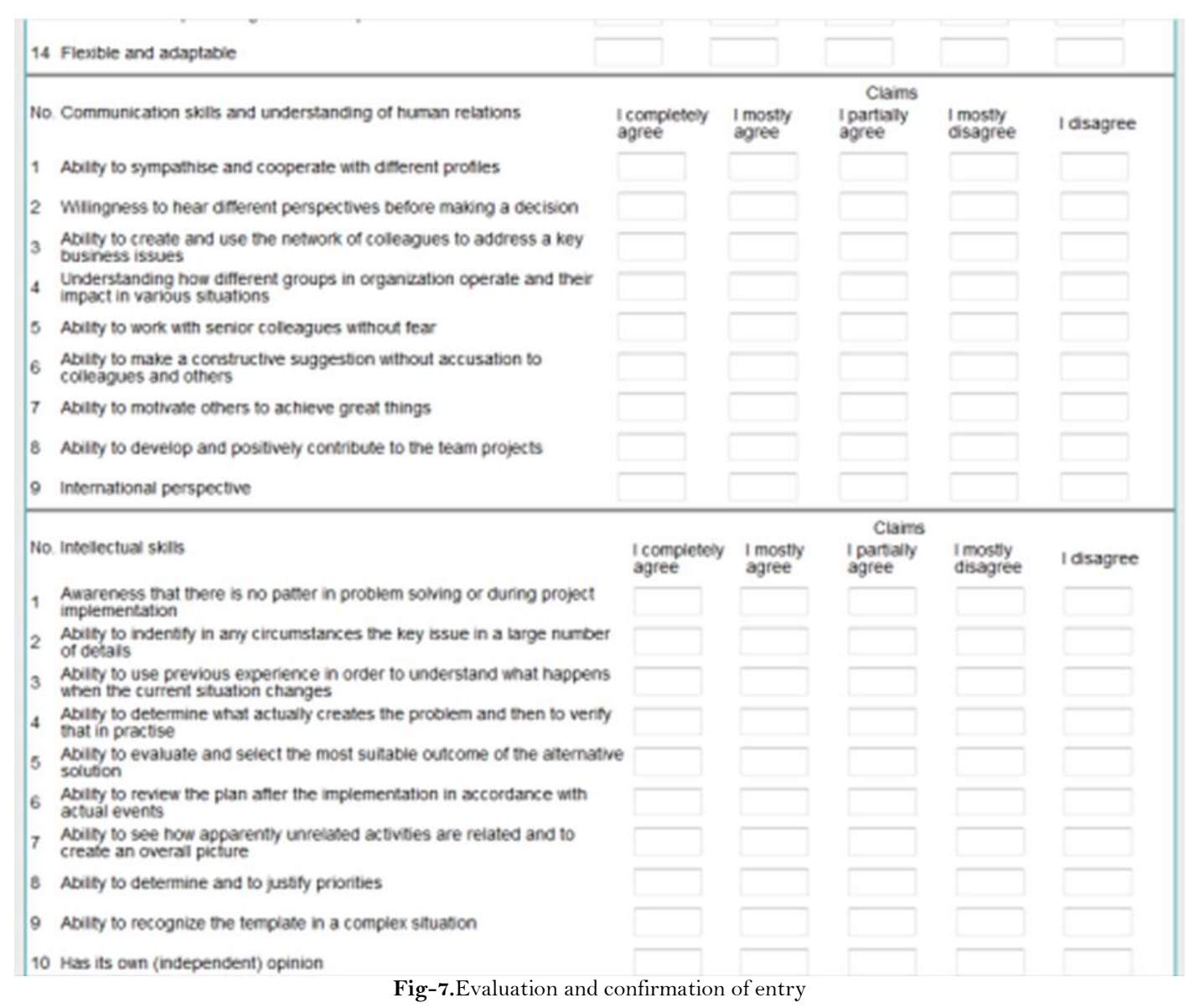

7. At the end it performs confirmation of entered responses, and data are stored in the database (Figure 7).

\section{Conclusion}

The basic idea of the research was to take advantage of IT and establish a direct contact between businesses (employers) and universities in order to exchange relevant data on the knowledge, skills and competencies of students who got their first job in the economy. Various research, studies, strategies and similar documents show that there is a discourse between the competencies acquired at the university and the need of ever more dynamic economy that is relatively quickly transformed in line with scientific and technological changes. On the other hand, many universities are still holding the old paradigm thus failing to provide the conditions for students to acquire knowledge, develop skills and abilities to work in the new "modified" conditions that require a different kind of competence.

Relying on existing theoretical knowledge we modeled the research, and we are in the first part we constructed an instrument (a questionnaire with 44 questions of Likert type), performed necessary determining of its metric values, and then created a web application for its easy use.

For programing we used PHP, HTML5. Javascript supported application's functionality. CSS was used for design, and all data are stored in a MySQL database.

The software was tested and when tested did not produce any mistakes.

In the next step we shall implement the software on universities and involve companies i.e. employers to provide feedback on the work of software and marks of students.

Further research will be based on the data obtained from employers, which will serve as a basis for solutions and theoretical generalization.

\section{References}

Andrews, D., B. Nonnecke and J. Preece, 2003. Electronic survey methodology, a case study in reaching hard to involve internet users. International Journal of Human-Computer Interaction, 16(2): 185-2 10. View at Google Scholar | View at Publisher

Andrews, J. and H. Higson, 2008. Graduate employability,'soft skills' versus 'hard'business knowledge: A European study. Higher Education in Europe, 33(4): 411-422. View at Google Scholar | View at Publisher

Association of Graduate Recruiters - AGR, 1995. Skills for graduates in the 21st century. Cambridge: AGR

Australian Association of Graduate Employers - AAGE., 1993. National survey of graduate employers. Sydney, Australia: AAGE.

Gobbi, M., 2005. Tuning educational structures in Europe - summary of outcomes: Nursing, Bilabo, Spain Tuning Project: 14. Retrieved from http://www.unideusto.org/tuning/.

Ministarstvo Civilnih Poslova BiH, 2011. Basics of the qualification framework in BiH. Official gazette of BiH. pp: 31 . Retrieved https://ec.europa.eu/epale/hr/resource-centre/content/osnove-kvalifikacijskog-okvira-u-bosni-i-hercegovini.

Schleyer, T.K.L. and J.L. Forrest, 2000. Methods for the design and administration of web-based surveys. Journal of the American Medical Informatics Association, 7(4): 416-425. View at Google Scholar |View at Publisher

Simeunović, V., 2009. Obrazovanje u funkciji privrednog razvoja u Republici Srpskoj. Naša Skola, 3-4: 235-266.

Theodore, W.S., 1961. Investment in human capital. American Economic Review, 51 1 (1): 1-1 7. View at Google Scholar

Vescio, J., 2005. An investigation of successful graduates in the early stages of their career across a wide rangeof professions. University of Technology Sidney. Retrieved from http://www.uws.edu.au/_data/assets/pdf_file/O019/7363/UTS_Succ_Grads_project_report_J.Vescio_2005.pdf.

Vlada Republike Srpske, 2015. Draft strategy for the development of education of Republika Srpska for the period 2015. - 2020 years. 